Disponível em:

http://editora.unoesc.edu.br/index.php/race

RACE, Joaçaba, v. 16, n. 3, p. 1059-1078, set./dez. 2017

\title{
A AUTOEXPRESSÃO COMO DIMENSÃO INOVADORA DE MOTIVAÇÃO NO COMPARTILHAMENTO DE VÍDEOS EM REDES SOCIAIS
}

Self-expression as motivation of innovative dimension in video sharing in social networks

Jéssica Motta

E-mail: jehcac@hotmail.com Mestre em Administração pela Fundação Universidade Regional de Blumenau; Bacharel em Administração pela Faculdade Sociedade Educacional de Santa Catarina; Técnico-administrativa em Educação no Instituto Federal Catarinense de Camboriú. Endereço para contato: Rua Joaquim Garcia, s/n, Centro, 88340-055, Camboriú, Santa Catarina, Brasil.

Edson Roberto Scharf

E-mail: artigoes@gmail.com Pós-doutor na Área de Marketing/Branding pela Universidade Federal de Santa Catarina; Doutor em Engenharia e Gestão do Conhecimento na Área de Marketing pela Universidade Federal de Santa Catarina; Professor Titular na Universidade Regional de Blumenau.

Artigo recebido em 21 de outubro de 2016. Aceito em 28 de agosto de 2017. 
Resumo

A troca de informações, conhecimentos e experiências sobre as marcas, bens e serviços entre os consumidores na internet é conhecida como boca a boca eletrônico ou e-Word of Mouth (eWOM). A autoexpressividade do consumidor foi associada ao aumento da interação social na rede social Facebook, por meio do compartilhamento de vídeos de campanhas publicitárias. Para tanto, fatores como autoexpressividade, autocongruência com a marca, nível de envolvimento do consumidor com a categoria de produtos e valor de entretenimento da mensagem poderão estar relacionados ao compartilhamento de vídeos empresariais. Desse modo, foi investigado se a autoexpressão é um dos motivadores para o compartilhamento de vídeos em redes sociais. Nesta pesquisa aplicou-se um questionário por meio de mensagens enviadas para consumidores que compartilharam dois vídeos em duas páginas distintas da rede social Faceboook. As hipóteses testadas nesta pesquisa, em uma análise estrutural geral, tiveram o valor de entretenimento da mensagem e o nível de autocongruência com a marca não rejeitados pelos cálculos estatísticos e tiveram o poder de explicação de 35,7\% (r2 0,357) relacionados à autoexpressão. Apesar do resultado, não pode ser comprovada a autoexpressão como dimensão inovadora de motivação para o compartilhamento espontâneo de vídeos em redes sociais.

Palavras-chave: Autoexpressão. Compartilhamento espontâneo de vídeos. Comunicação eWOM. Rede social. Estratégia inovadora de comunicação.

\section{Abstract}

The exchange of information, knowledge and experience about the brands, goods and services among consumers on the internet is known as mouth-to-mouth electronic or e-Word of Mouth (eWOM). Consumer self-expression was associated with increased social interaction in the social network Facebook, through the sharing of video advertising campaigns. Therefore, factors such as self-expression, self-congruence with the brand, the consumer's level of involvement with the product category and the message of the entertainment value, may be related to the sharing of corporate videos. Thus, it was investigated if the self-expression is one of the motivators for sharing videos on social networks. This research applied a questionnaire through messages sent to consumers who shared two videos in two different pages Facebook social network. The hypothesis tested in this study in a general structural analysis have the entertainment value of the message and level of self-congruence with the brand not rejected by statistical calculations, and had the power to 35.7\% explanation ( $\left.r^{2} 0.357\right)$ related to selfexpression. Despite the result it can not be proven self-expression as an innovative dimension of motivation for spontaneous sharing videos on social networks.

Keywords: Self-expression. Spontaneous sharing videos. Communication eWOM. Social network. Innovative communication strategy. 


\section{INTRODUÇÃO}

O surgimento da World Wide Web (Web 2.0) efetivou a participação de usuários - internautas - e impulsionou o aparecimento das chamadas mídias sociais. A rede social está inserida no ambiente mídia social, que consiste em "um grupo de aplicações para Internet, construídas com base nos fundamentos ideológicos e tecnológicos da Web 2.0, e que permitem a criação e troca de Conteúdo Gerado pelo Utilizador.” (KAPLAN; HAENLEIN, 2010, p. 61).

Por intermédio da internet as mídias sociais potencializaram a forma de comunicação entre as empresas e consumidores, bem como entre consumidores e consumidores. A troca de informações, conhecimentos e experiências sobre as marcas, bens e serviços entre os consumidores na internet é conhecida como boca a boca eletrônico ou $e$-Word of Mouth (eWOM) (HENNIG-THURAU et al., 2004).

Diferente do boca a boca convencional, o eWOM facilita a disponibilização de qualquer informação de um consumidor, negativa ou positiva, e esta pode ser disponibilizada para outros potenciais reais ou ex-clientes da marca ou produto em questão. Toda declaração feita é a transcrição de uma experiência ou dúvida vivenciada sobre determinado produto (HENNIG-THURAU et al., 2004).

Há indícios de que a motivação, fenômeno que ocorre ao despertar de uma necessidade, é um dos principais indicativos de alteração do comportamento do consumidor (PINHEIRO, 2006, BLACKWELL; MINIARD; ENGEL, 2011). É possível saber que nas redes sociais existem algumas necessidades de expressão na comunicação interpessoal, sendo elas: necessidade de pertencimento a um grupo (inclusão); de demonstrar afeto e preocupação com os demais (altruísmo); e de aparentar domínio e poder sobre o grupo pertencido (SCHUTZ, 1966).

Taylor, Strutton e Thompson (2012) propuseram um modelo em que buscaram avaliar a possibilidade de o compartilhamento de mensagens on-line estar relacionado ao valor do entretenimento, envolvimento com o produto, congruência self e marca e autoexpressão. Para os autores, a identidade é um dos fatores motivadores do compartilhamento, e as empresas devem conectar as propriedades simbólicas inseridas em seus produtos ou marcas ao autoconceito do consumidor.

No presente estudo se recorreu à Teoria da Identidade, baseada no modelo proposto por Taylor, Strutton e Thompson (2012) e replicado com base na dissertação de Ivo (2014). Nesses trabalhos, a autoexpressividade do consumidor foi associada ao aumento da interação social na rede social Facebook, por meio do compartilhamento de vídeos empresariais. 
Para tanto, fatores como autoexpressividade, autocongruência com a marca, nível de envolvimento do consumidor com a categoria de produtos e valor de entretenimento da mensagem poderão estar relacionados ao compartilhamento de vídeos empresariais.

Desse modo, o objetivo com o presente estudo foi confirmar a autoexpressão como dimensão inovadora de motivação no compartilhamento de vídeos em redes sociais. Para tanto, realizou-se o seguinte questionamento: a dimensão inovadora autoexpressão é motivadora para o compartilhamento de vídeos empresariais?

\section{REVISÃO DA LITERATURA}

Nesta seção são abordados assuntos relacionados ao surgimento da internet e das redes sociais on-line. Em seguida são explicitadas as diferenças do boca a boca convencional para o boca a boca eletrônico e, ao final, as emoções como motivadoras de comportamento.

\subsection{REDES SOCIAIS E COMUNICAÇÃO WORD OF MOUTH (WOM)}

É possível encontrar como sinônimas as expressões Mídia social e Rede social, porém Kaplan e Haenlein (2010, p. 63) explicam que existe diferença entre as duas. A mídia social é caracterizada por um grupo de pessoas participantes, as quais possuem perfis com informações pessoais. Estes possibilitam o acesso de pessoas que também possuem perfis com informações, no mesmo site. A mídia social é o ambiente em que as redes sociais estão inseridas.

Barichello e Oliveira (2010, p. 32) ressaltam a importância do entendimento sobre a linguagem utilizada nesse ambiente, e que por meio dela é possível compreender as formas culturais e as representações sociais desenvolvidas a partir das interações dos usuários. Diante desse contexto surge uma nova "ambiência, em que o receptor também exerce papel relevante na comunicação.”

A liberdade de acesso à internet e ao grande montante de informações disponíveis por ela acabou descentralizando a partida da informação, impulsionada pelas mídias sociais. Barichello e Oliveira (2010, p. 32) evidenciam que passa a se tornar emissor quem antes era apenas considerado receptor no processo de comunicação. Esse ambiente permitiu ao internauta a produção de conteúdos e a disseminação deles, com opiniões e pontos de vista "nunca antes vistos/ouvidos/lidos nos meios tradicionais” de comunicação. 
A troca de informações, conhecimentos e experiências sobre marcas e bens entre os consumidores é conhecida como Word of Mouth, doravante denominada WOM. Entre as definições mais antigas sobre WOM, podem ser mencionados os autores Katz e Lazarsfeld (1955), que o definiram como a troca de informações de marketing entre consumidores, a qual poderia influenciar a atitude e o comportamento dos consumidores sobre o bem ou serviço.

O WOM on-line (eWOM) é definido por Hennig-Thurau et al. (2004, p. 39) como "qualquer declaração positiva ou negativa feita por potenciais, reais, ou ex-clientes sobre um produto ou empresa, que é disponibilizado para uma multidão de pessoas e instituições através da Internet.” A declaração feita pelo consumidor se trata da experiência adquirida por meio do uso do bem ou serviço.

O grande poder de abrangência da comunicação eWOM, o material produzido em sua decorrência e a disponibilidade de tempo de exposição à internet podem gerar um ambiente favorável ou não para as empresas. Hennig-Thurau et al. (2004, p. 42) explicam que as observações negativas feitas a um determinado produto ou serviço podem influenciar a percepção da imagem da empresa. “As articulações públicas, podem ser utilizadas pelos consumidores como um instrumento de poder.”

Cyrot, Urdl e Alves (2005) começam por definir essa ação de compartilhamento espontâneo como uma estratégia que influencia o indivíduo a repassar a mensagem para outros, potencializando a exposição desta e a influência para novos repasses.

Para Barichello e Oliveira (2010), o compartilhamento está totalmente associado ao meio de comunicação on-line e tem a finalidade de propiciar aos consumidores e internautas o espontâneo compartilhamento do conteúdo e, ao mesmo tempo, promover a marca.

\subsection{EMOÇÕES COMO MOTIVADORAS DE COMPORTAMENTO}

Há a necessidade do estudo do comportamento do consumidor, na tentativa de habilitar as empresas a atraírem seus clientes, satisfazê-los e retê-los, com o intuito de aumentar as vendas e maximizar os lucros. Solomon (2016, p. 6) define o comportamento do consumidor como sendo "o estudo dos processos envolvidos quando indivíduos ou grupos selecionam, compram, usam ou descartam produtos, serviços, ideias ou experiências para satisfazerem necessidades e desejos.”

Criador da Teoria FIRO (Fundamental Interpersonal Relationships Orientation), obra que aborda sobre o comportamento tridimensional interpessoal, Schutz (1966) propôs uma abordagem facilitadora para o entendimento sobre a dinâmica do 
comportamento humano. Sugeriu os três principais motivadores para que ocorra a necessidade de expressão na comunicação interpessoal: inclusão - há a necessidade de pertencer a um grupo e ter a atenção dele; afeto - também existe a necessidade de o indivíduo demonstrar preocupação e consideração com os demais; e controle - o indivíduo precisa demonstrar domínio e poder no grupo social inserido.

Dobele et al. (2007) concluíram que as mensagens on-line necessitam transmitir a surpresa, porém tal elemento não é suficiente. A surpresa deverá ser combinada com outras emoções as quais podem estar relacionadas ao gênero. Por exemplo, mensagens que transmitem desgosto ou medo são mais propensas de serem compartilhadas por pessoas do gênero masculino, e as experiências emocionais estão relacionadas à cultura em que o internauta está inserido. Além desses sentimentos, complementam Barichello e Oliveira (2010) que informações úteis e conteúdos relevantes e instigadores também devem fazer parte de uma mensagem que tende a ser amplamente compartilhada por espontaneidade.

Na partilha das mensagens, Taylor, Strutton e Thompson (2012, p. 1) identificam o sentido de identidade como um dos fatores de motivação. "Os comerciantes têm a percepção de que os consumidores compram produtos não apenas para os seus benefícios práticos ou utilitários, mas também por seu valor simbólico.” A mensagem deve considerar as propriedades simbólicas e a autoexpressividade do conteúdo exibido, a fim de conectá-las ao autoconceito do usuário.

Sirgy (1982, p. 282) explica que o autoconceito é entendido como a percepção que o consumidor tem de si mesmo, ou seja, é definido como o “"verdadeiro eu’, o ‘eu real'.” Complementa que para alguns pesquisadores o autoconceito possui dois componentes: o real e o ideal. O real é a verdadeira percepção do auto, e o ideal é como o consumidor gostaria de ser, voltado para uma “imagem idealizada” e “autodesejado".

Taylor, Strutton e Thompson (2012) explicam que a autoexpressividade expande o conceito de que o consumidor, ao comprar um bem, está reconhecendo publicamente que este coincide com seu autoconceito. Desse modo, faz sentido expressar que a comunicação eWOM, gerada pelo compartilhamento de mensagens pelo indivíduo, é entendida como capaz de expressar o auto do indivíduo.

O valor de entretenimento de um vídeo significa o grau em "que um anúncio online proporciona prazer, diversão, ou entretenimento para os consumidores.” (TAYLOR; STRUTTON; THOMPSON, 2012, p. 17). O valor de entretenimento da mensagem também está relacionado com o significado que ela transmite ao internauta e, dessa forma, está relacionado à identidade. 
Taylor, Strutton e Thompson (2012, p. 17) complementam que o que as pessoas acham divertido reflete quem elas são, como elas se veem e como elas são percebidos pelos outros, e exemplificam dizendo que um consumidor que acredita ser moderno e elegante compartilhará anúncios recentes que apresentam características modernas e elegantes, expressando seu autoconceito.

Kapferer e Laurent (1985) conceituam o envolvimento com o produto como o grau de importância que o consumidor atribui a um produto, propaganda, decisão de compra em razão de suas necessidades, interesses e valor atribuído ao bem. Quando o consumidor possui pouco envolvimento com a categoria de produto, os valores de ligação entre o consumidor e o envolvimento se tornam baixos, já que o comprometimento do consumidor com a marca é baixo.

Taylor, Strutton e Thompson (2012) comentam que o envolvimento da categoria do produto está também relacionado à autoexpressão, pois o que é de extrema importância para o consumidor acaba, de certa forma, relacionado ao seu autoconceito. Estudos realizados por Sundaram, Mitra e Webster (1998) concluíram que os principais motivos de envolvimento com o produto os quais propiciaram a comunicação eWOM positiva foram desencadeados por experiências vivenciadas com os produtos.

Autoexpressão é um fenômeno conectado à comunicação humana. Para Bedbury e Fenichell (2002) e Aaker e McLoughlin (2007), está relacionada a aspectos como individualidade, personalidade e idiossincrasias do indivíduo. A autoexpressão é estudada em áreas distintas das ciências sociais como o marketing (AAKER, 1999), a psicologia (LANDAU et al., 2011) e a educação (TOBIN, 1995). Também em áreas como a moda são apresentados estudos, conforme os de Velliquette, Murray e Evers (2006), para quem as várias maneiras de modificação corporal, temporárias ou permanentes, são utilizadas para se autoexpressar no seu meio.

Um indivíduo adota papéis distintos em determinados períodos e pode assumir autoimagens diferentes em cada um deles, com expressões próprias para cada momento (AAKER; MCLOUGHLIN, 2007). Segundo os autores, quando uma marca permite o benefício da autoexpressão, a relação entre ela e quem a consome é enriquecida. Uma marca, nesse contexto, proporciona sensações únicas, que comunicam o modo de ser da pessoa no meio em que ela vive.

Para Holt (2002), as marcas, anteriormente identificadoras de um produto por sua utilidade, suprem o bem de consumo com uma acentuada carga simbólica, atuando como canais de autoexpressão que contribuem para a construção da identidade do consumidor. Segundo Landau et al. (2011), a linguagem é um campo fértil de 
autoexpressão, posto que é um conjunto de representações simbólicas aplicado ao que é comunicado pelas pessoas.

Sirgy, Grewal e Mangleburg (2000) explicam que o processo de ligação entre o autoconceito do consumidor e a imagem transmitida pela marca, com a probabilidade de o consumidor desenvolver uma atitude positiva em relação à marca, é conhecido como processo de congruência de autoimagem, ou seja, autocongruência.

Para Sirgy (1982), quando o consumidor tem em mente o tipo de imagem que ele quer expressar em um contexto social, procura maneiras de divulgá-la. O consumo de um determinado produto é um meio de expressar a autoimagem a fim de manter a autoestima elevada; o consumidor optará por comprar produtos valorizados positivamente. Desse modo, cabe observar que o consumo de uma marca está diretamente relacionado à autocongruência do consumidor.

O gestor que almeja a liderança de uma marca acaba por buscar um papel visionário e estratégico, pois, para que a liderança aconteça, é necessário que "ele assuma o controle da marca de forma estratégica, determinando o que ela deve representar aos olhos do cliente.” (AAKER, JOACHIMSTHALER, 2007, p. 28). A qualidade percebida é um tipo de associação que o consumidor faz com a marca. As associações de marca dependem de qualquer fato que vincule o cliente à marca, e a lealdade à marca é o valor particular que cada consumidor aplica sobre ela (AAKER, JOACHIMSTHALER, 2007, p. 28; TAYLOR; STRUTTON; THOMPSON, 2012).

Para Keller (1993, p. 4-5), as atitudes da marca também são importantes para a formação da base do comportamento do consumidor. Elas criam no consumidor expectativas que podem amplificar os seguintes conceitos: “(1) as crenças salientes, que o consumidor tem sobre o bem ou serviço (isto é, a extensão a que os consumidores pensam que a marca tem em certos atributos ou benefícios) e (2) o julgamento avaliativo dessas crenças (ou seja, o quão bom ou ruim é que a marca tem esses atributos ou benefícios).” O autor complementa que as atitudes da marca servem como uma função de "valor expressivo", o que faz com que os consumidores expressem seus autoconceitos.

\section{METODOLOGIA}

Para esta pesquisa descritiva foram escolhidas duas páginas com grande circulação na rede social Facebook que publicaram os vídeos da pesquisa em momento anterior. A pesquisa foi enviada através de mensagem para cada perfil de usuário do Facebook que compartilhou cada vídeo. Essa mensagem partiu de um perfil e con- 
tinha um informe da participação na pesquisa, seguido do agradecimento, com o link do vídeo, caso o participante sentisse necessidade de relembrar a mensagem do vídeo e um link, que conduzia o internauta a uma página do Google com um questionário referente à pesquisa.

Os vídeos selecionados foram vencedores do Grand Prix 2015.

a) Vídeo 1: Volvo Trucks - venceu a categoria que premia campanhas com impacto comprovado sobre o comportamento dos consumidores e lucratividade da marca. Teve mais de 100 milhões de visualizações. No vídeo o ator Jean Claude Van Damme faz espacate apoiado entre dois caminhões da marca Volvo, mostrando a estabilidade dos veículos.

b) Vídeo 2: “Lifepaints” da Grey Londres para Volvo - também é um vídeo da marca Volvo que venceu a categoria Design e Promo\&Activation. “Trata-se de um spray que melhora a visibilidade de objetos à noite. A solução é voltada para ciclistas, que ficam mais protegidos. A ação teve participação da start up Albedo100, o que mostra o quanto a publicidade pode ganhar ao se aproximar de empresas de tecnologia.” (CANNES LIONS, 2015).

Para a análise dos dados, foram utilizados o Statistical Package for the Social Sciences (SPSS) versão 21 e o IBM® SPSS® Amos (IBM CORPORATION, 2012). Ambos os softwares foram necessários para a análise estatística avançada, permitindo avaliar e estimar modelos relacionando as variáveis entre si por meio da análise descritiva e fatorial confirmatória.

De acordo com o proposto por Taylor, Strutton e Thompson (2012), este estudo recorreu à Teoria da Identidade de George Herbert Mead, aplicada à propensão da comunicação eWOM. A autoexpressividade do consumidor foi associada ao aumento da interação social na rede social Facebook, mediante o compartilhamento de vídeos empresariais.

Sendo a comunicação WOM uma ação amplamente relacionada ao aspecto social, baseado nos estudos de Taylor, Strutton e Thompson (2012), foram testadas as hipóteses a respeito de: os consumidores percebem que ao compartilharem uma campanha publicitária expressarão sua identidade para os membros da sua rede de relacionamento; este será o determinante na propensão ao compartilhamento dos vídeos; após, o valor de entretenimento da mensagem, bem como a relação entre a marca e a self e o nível de envolvimento do consumidor com a categoria de produto, serão com- 
plementos, na identificação da propensão ao compartilhamento. Seguem elencadas as hipóteses da pesquisa:
a) H1: o valor do entretenimento da mensagem tem efeito positivo direto sobre a autoexpressividade da mensagem;
b) H2: o nível de envolvimento com a categoria de produto tem efeito posi- tivo direto sobre a autoexpressividade da mensagem;
c) H3: o nível de autocongruência com a marca tem efeito positivo sobre a autoexpressividade da mensagem.

\section{ANÁLISE DOS DADOS}

De modo geral, o perfil dos respondentes desta pesquisa foi, em sua maioria, mulheres representando 54\%; solteiros com representatividade de 45,67\%; idade entre 17 e 45 anos, sendo 84,2\%; e com renda bruta familiar variando entre R\$1.501,00 e R\$ 5.000,00, correspondendo a 60,6\% dos questionados.

Depois do refinamento, ou seja, a retirada dos fatores que apresentaram pouca representatividade, bastaram no modelo apenas as questões com cargas padronizadas maiores que 0,7 e significância maior que 95\%, conforme sugerido pela literatura.

A Tabela 1 descreve sobre a confiabilidade dos constructos, verificados por meio do Alfa de Cronbach, a confiabilidade composta e a Análise da Variância Extraída (AVE), os quais precisam ter indicadores maiores que 0,7, 0,7 e 0,5, respectivamente.

Tabela 1 - Confiabilidade

\begin{tabular}{lrrr}
\hline \multicolumn{1}{c}{ Dimensão } & $\begin{array}{c}\text { Alfa de } \\
\text { Cronbach }\end{array}$ & Confiabilidade composta & AVE \\
\hline Valor de Entretenimento & 0,903 & 0,910 & 0,77 \\
Auto-Expressão & 0,946 & 0,950 & 0,78 \\
Envolvimento & 0,951 & 0,950 & 0,87 \\
Congruência self e marca & 0,956 & 0,960 & 0,84 \\
\hline Fonte: os autores. & & &
\end{tabular}

O Alfa de Cronbach de todos as dimensões apresenta valores maiores que o mínimo exigido pela literatura, 0,7. Ressalta-se que quanto mais próximo de 1 , maior a fidedignidade das dimensões. Nesta pesquisa todos estavam acima de 0,9, bem como nos valores da confiabilidade composta. Todos os constructos foram validados com base na AVE cujos valores precisam estar acima de 0,7. Desse modo, os 
constructos apresentaram convergência interna, já que os indicadores estavam conforme o sugerido pela literatura.

O Quadro 1 apresenta, de forma resumida, os achados por esta pesquisa separados por vídeo 1, Volvo Trucks, e vídeo 2, Lifepaint.

Quadro 1 - Resumo dos achados

\begin{tabular}{|c|c|c|}
\hline Descrição & Vídeo & Análise \\
\hline \multirow{2}{*}{$\begin{array}{l}\text { Análise des- } \\
\text { critiva das } \\
\text { variáveis dos } \\
\text { constructos }\end{array}$} & Vídeo 1, Volvo Trucks & $\begin{array}{l}\text { As dimensões "Valor de entretenimento" e "Envolvimento } \\
\text { com a categoria de produto" tiveram respostas médias } \\
\text { entre } 4 \text { e } 5 \text { (concordo e concordo totalmente); para a au- } \\
\text { toexpressão foram neutras, com valores próximos a } 3 \text { (não } \\
\text { concordo e nem discordo) e a "Congruência self e marca" } \\
\text { tiveram respostas entre } 2 \text { e } 3 \text { (não concordo e não concor- } \\
\text { do e nem discordo). }\end{array}$ \\
\hline & Vídeo 2, Lifepaint & $\begin{array}{l}\text { As dimensões “Autoexpressão” e “Congruência self e mar- } \\
\text { ca” tiveram respostas médias próximas a } 3 \text { (não concordo e } \\
\text { nem discordo), a "Valor de entretenimento” foi próxima a } \\
5 \text { (concordo totalmente) e a “Envolvimento com a catego- } \\
\text { ria de produto” próxima a } 4 \text { (concordo). }\end{array}$ \\
\hline \multirow{2}{*}{$\begin{array}{l}\text { Valor de entre- } \\
\text { tenimento da } \\
\text { mensagem }\end{array}$} & Vídeo 1, Volvo Trucks & $\begin{array}{l}\text { Não apresentou significância em relação à autoexpressão, } \\
\text { pois o p-value foi superior a } 0,05 \text {. }\end{array}$ \\
\hline & Vídeo 2, Lifepaint & $\begin{array}{l}\text { Não apresentou significância em relação à autoexpressão, } \\
\text { pois o p-value foi superior a } 0,05 \text {. }\end{array}$ \\
\hline \multirow{2}{*}{$\begin{array}{l}\text { Envolvimento } \\
\text { com a catego- } \\
\text { ria do produto }\end{array}$} & Vídeo 1, Volvo Trucks & $\begin{array}{l}\text { Não apresentou significância em relação à autoexpressão, } \\
\text { pois o p-value foi superior a } 0,05 \text {. }\end{array}$ \\
\hline & Vídeo 2, Lifepaint & $\begin{array}{l}\text { Não apresentou significância em relação à autoexpressão, } \\
\text { pois o p-value foi superior a } 0,05 \text {. }\end{array}$ \\
\hline \multirow{2}{*}{$\begin{array}{l}\text { Congruência } \\
\text { self e marca }\end{array}$} & Vídeo 1, Volvo Trucks & $\begin{array}{l}\text { Apresentou significância em relação à autoexpressão, pois } \\
\text { o p-value foi igual a } 0 \text {. }\end{array}$ \\
\hline & Vídeo 2, Lifepaint & $\begin{array}{l}\text { Apresentou significância em relação à autoexpressão, pois } \\
\text { o p-value foi igual a } 0 \text {. }\end{array}$ \\
\hline Autoexpressão & $\begin{array}{l}\text { Vídeo 1, Volvo Tru- } \\
\text { cks e } \\
\text { Vídeo 2, Lifepaint }\end{array}$ & $\begin{array}{l}\text { As hipóteses testadas nesta pesquisa em uma análise estru- } \\
\text { tural geral tiveram o valor de entretenimento da mensagem } \\
\text { em relação à autoexpressividade não rejeitado pelos cál- } \\
\text { culos estatísticos, bem como o nível de autocongruência } \\
\text { com a marca e o poder de explicação de apenas 35,7\% (r2 } \\
\text { 0,357), relacionados à autoexpressão, que, de acordo com } \\
\text { Barbetta (1998), esse valor é considerado “fraco” no que } \\
\text { diz respeito à força da correlação das variáveis dependen- } \\
\text { tes com a independente. }\end{array}$ \\
\hline
\end{tabular}

Fonte: os autores.

O modelo de equações estruturais se apresentou de forma geral (somando os dados dos dois vídeos) e de maneira separada, por vídeo compartilhado. A partir desse momento, foi possível confirmar, ou não, o proposto pela teoria. As variáveis preci- 
sam ter um nível de significância superior a 95\%, o que na Tabela 2 é demonstrado por valores de $p$-value abaixo de 0,05 .

A Tabela 2 apresenta a relação de significância da variável "Valor do entretenimento, envolvimento e congruência” relacionada à autoexpressão do internauta, a qual é a variável dependente.

Tabela 2 - Análise estrutural Geral - variável dependente: autoexpressão

\begin{tabular}{lrrr}
\hline Explicativas & Carga padronizada & P-value & \multicolumn{2}{c}{ R2 } \\
\hline Valor do entretenimento & 0,180 & 0,023 & 0,357 \\
Envolvimento & 0,033 & 0,669 & \\
Congruência & 0,569 & $* * *$ & \\
Fonte: os autores. & & &
\end{tabular}

A Tabela 2 apresentou a análise dos dois vídeos. De modo geral, o envolvimento não foi significante, pois teve o $P$-value maior que 0,05 , $(p>0,05)$ sendo este 0,669. O valor do entretenimento e congruência foram significativos, com valores abaixo de 0,05. Quanto à carga padronizada, o valor do entretenimento e a congruência foram significantes, pois possuem uma relação de 0,18 e 0,569 com a variável dependente autoexpressão, respectivamente. As duas variáveis explicam a autoexpressão em 35,7\% (r2 0,357), que, de acordo com Barbetta (1998), esse valor é considerado “fraco” no que diz respeito à força da correlação das variáveis independentes (valor do entretenimento, envolvimento e congruência) com a variável dependente (autoexpressão).

Para Dobele et al. (2007), além de surpresa, as mensagens para serem compartilhadas precisam transmitir emoções, e estas poderão estar relacionadas ao gênero e ao fator cultural. Phelps et al. (2004) e Barichello e Oliveira (2010), em seus trabalhos, garantem que esses fatores, relacionados ao entretenimento, são grandes influenciadores para o compartilhamento espontâneo das mensagens on-line.

O trabalho de Taylor, Strutton e Thompson (2012) não apresentou significância nessa variável, porém não rejeitou a hipótese de que o entretenimento tem efeito positivo direto sobre a autoexpressividade da mensagem. Ivo (2014), no ajuste do modelo estrutural, apresentou significância na variável "Valor de entretenimento" e também não rejeitou a hipótese.

Em relação ao constructo envolvimento com a categoria do produto, este estudo apresentou nas análises estruturais de ambos os vídeos significância maior que 0,05 ( $>>0,05)$, o que vai de encontro aos estudos de Taylor, Strutton e Thompson (2012) e de Ivo (2014). Porém, na análise estrutural geral, Taylor, Strutton e Thomp- 
son (2012) não rejeitaram a hipótese de que “o nível de envolvimento com a categoria de produto tem efeito positivo direto sobre a autoexpressividade da mensagem”, e Ivo (2014) rejeitou, assim como nesta pesquisa.

Kapferer e Laurent (1985) explicam que se o consumidor possui pouco envolvimento com a categoria do produto, seus valores de ligação se tornam baixos, o que dificulta na propagação da mensagem on-line. Nesta pesquisa, os respondentes não se sentiram atraídos pela categoria de produtos apresentada em ambos os vídeos. Para Sirgy (1982), o internauta pode ter um envolvimento duradouro com a categoria de produto quando este está relacionado à marca envolvida, e a utilização de produtos dela pode provocar prazer.

No que diz respeito à hipótese, “o nível de autocongruência com a marca tem efeito positivo sobre a autoexpressividade da mensagem”; nesta pesquisa não se rejeitou a variável, pois na análise estrutural, em ambos os vídeos, o valor de $p$-value teve significância menor que 0,05 ( $<<0,05)$ com confiabilidade maior que 95\%. Para essa variável, Taylor, Strutton e Thompson (2012) e Ivo (2014) tiveram significâncias positivas e também não rejeitaram a hipótese testada.

De acordo com os estudos de Keller (1993, p. 5), o comportamento do consumidor é o resultante sobre o autoconceito do consumidor em relação à marca. $\mathrm{O}$ julgamento e a crença que o consumidor tem quanto a uma determinada marca terão um forte valor expressivo no repasse de suas convicções.

Autores como Bentivegna (2002), Barichello e Oliveira (2010), Camarero e San José (2011) e Pérez (2014) pesquisaram na tentativa de identificar características, técnicas, modelos e ações que facilitassem na disseminação espontânea de vídeos on-line, bem como Sirgy, Aguirre e Bosnjak (2012), Taylor, Strutton e Thompson (2012), Ivo (2014), Klein (2015) e Wright (2015) estudaram os motivadores do compartilhamento com outros, de conteúdos disponíveis na internet. A princípio, diante dos diversos resultados, identifica-se uma incógnita, na diretriz que transforma uma campanha publicitária em um vídeo de sucesso amplamente disseminado.

Na avaliação da variável entretenimento, as emoções de humor, prazer, diversão, interesse e curiosidade foram estimuladas com a apresentação dos vídeos, o que significa que a habilidade de externalizar a emoção sentida está relacionada ao conteúdo assistido e ao quão importante o conteúdo é para o espectador.

Este trabalho também possibilitou verificar o envolvimento do consumidor com a categoria de produto e sua relação com a probabilidade de compartilhamento de vídeos em redes sociais. Em ambos os vídeos, o valor de $p$-value foi maior que 0,05 ( $\mathrm{p}>0,05)$, e a hipótese foi rejeitada, ou seja, não foi constatada a relação entre o 
envolvimento do consumidor com a categoria de produto e a probabilidade de compartilhamento de vídeos. Foi observado também que o envolvimento dos respondentes com a categoria do produto era transitório, ou seja, estavam relacionados com suas experiências pessoais com a marca e não com o produto.

Ao investigar o quanto a autocongruência do consumidor com a marca influencia a probabilidade de compartilhamento de vídeos em redes sociais, foi identificado que em ambos os vídeos houve influência estatisticamente significativa $(p<0,05)$. $\mathrm{O}$ fato de ambos os vídeos pertencerem à mesma marca aumentou a credibilidade do achado. Para as empresas que divulgam suas marcas nesse ambiente midiático, vale considerar que os seus públicos tendem a compartilhar suas mensagens quando realmente gostam da marca, principalmente quando a mensagem vai ao encontro do autoconceito do consumidor.

Com o vídeo da Lifepaint, verificou-se que o consumidor, ao relacionar a confiabilidade e a segurança de uma marca automotiva conhecida a um produto que transmite um conceito de segurança e preocupação social, realizou a ação do compartilhamento, ainda que o consumidor apresente tendência altruísta.

\section{CONCLUSÃO}

O objetivo deste estudo foi confirmar a autoexpressão como dimensão inovadora de motivação no compartilhamento de vídeos em redes sociais. A partir dos resultados obtidos, foi possível observar como significativa a relação entre o valor de entretenimento das campanhas publicitárias estudadas e a probabilidade de compartilhamento de vídeos na rede social Facebook.

Apesar de que duas das três dimensões avaliadas apresentaram resultados significativos $(\mathrm{p}<0,05)$, quando avaliadas de forma isolada, não foi comprovada a autoexpressão como fator motivador para o compartilhamento de vídeos no Facebook. As duas variáveis não rejeitadas (valor de entretenimento e congruência self e marca) tiveram uma explicação considerada estatisticamente "fraca” (r2 0,357) em relação à autoexpressão do consumidor como fator motivador para o compartilhamento de vídeos empresariais.

Apesar de Taylor, Strutton e Thompson (2012) terem conseguido comprovar em sua pesquisa que o compartilhamento de mensagens tem como motivação a autoexpressão, Ivo (2014) não comprovou o mesmo resultado, já que suas variáveis possuíam explicação considerada estatisticamente “fraca” (r2 0,464) em relação à autoexpressividade, semelhante a esta pesquisa. 
Ainda que os vídeos empresariais amplamente divulgados possuam grande audiência nas ambiências midiáticas, muito ainda precisa ser estudado a fim de delimitar os determinantes para um vídeo de sucesso. Ocorre que fatores como relação do consumidor com a marca e entretenimento são facilitadores para o compartilhamento, porém ainda não apoiam a explicação sobre a autoexpressão. Para identificar o que motiva o compartilhamento serão necessários novos experimentos com outros públicos, outros vídeos e análise destes e de outros fatores.

É de interesse das empresas que buscam um relacionamento com seus consumidores por meio do ambiente on-line divulgarem sua marca e suas ações por meio de compartilhamento espontâneo de materiais. Para tanto, os estudos referentes ao tema, bem como o desta pesquisa, sugerem que a mensagem precisa ter um efeito positivo ao passo que o internauta assume o custo de repassá-la.

O meio em que esta pesquisa foi aplicada, a rede social Facebook, é um ambiente geralmente utilizado para lazer e que possui algumas ferramentas que dificultam o acesso e/ou a troca de informação com qualquer perfil ou conta cadastrada nessa rede social. Diante das características restritivas de acesso, a margem de erro de 12\% foi um fator limitante, e também a aplicação em apenas uma mídia social (Facebook). Seria necessária a aplicação em outras mídias sociais para alcançar novos resultados.

É possível saber que o que faz um consumidor escolher determinado bem/ serviço está relacionado com suas experiências já vivenciadas, bem como com os valores simbólicos a ele atribuídos. Na divulgação da mensagem captada por um vídeo empresarial, há a necessidade do estabelecimento de uma conexão com o internauta, seja por meio da emoção, do valor de entretenimento, do envolvimento com a categoria de produto ou com a marca, seja possivelmente com outras características que ainda surgirão.

O resultado deste estudo diverge do apresentado por Taylor, Strutton e Thompson (2012) e se assemelha ao de Ivo (2014), porém é aplicado para grupos diferentes, pertencentes a culturas diferentes, e de forma diferente. É essencial que pesquisas futuras apliquem esse modelo de outros modos para convalidar as informações às pesquisas já realizadas. A aplicação deste trabalho em outras mídias sociais como Instagram, Twitter, WhatsApp, Snapchat, Google Plus é importante para auxiliar na validação dos achados.

O estudo de Dobele et al. (2007) sugere que as experiências emocionais estão relacionadas à cultura do indivíduo, bem como a surpresa e outras emoções podem sofrer interferência dependendo do gênero. Pesquisas aplicadas em ambientes diferentes e que garantam o teste das características relatadas podem chegar a resultados 
diferentes. Vídeos com propósitos e ambientes diferentes também podem ajudar na construção de novos conceitos para a temática.

\section{REFERÊNCIAS}

AAKER, D. A.; JOACHIMSTHALER, E. Como construir marcas líderes. Porto Alegre: Bookman, 2007.

AAKER, D. A.; MCLOUGHLIN, D. Strategic market management. West Sussex: John Wiley \& Sons, 2007.

AAKER, J. L. The malleable self: the role of self-expression in persuasion. Journal of Marketing Research, v. 36, i. 1, p. 45-57, 1999.

BARBETTA, P. A. Estatística Aplicada às Ciências Sociais. Florianópolis: Ed. UFSC, 1998.

BARICHELLO, E.; OLIVEIRA, C. C. O marketing viral como estratégia publicitária nas novas ambiências midiáticas, v. 14, n. 1, p. 29-44, 2010.

BEDBURY, S.; FENICHELL, S. O novo mundo das marcas. Rio de Janeiro: Campus, 2002.

BENTIVEGNA, F. J. Fatores de impacto no sucesso do marketing boca a boca online. Revista de Administração de Empresas, São Paulo, v. 42, n. 1, p. 79-87, jan./ mar. 2002.

BLACKWELL, R. D.; MINIARD, P. W.; ENGEL, J. F. Comportamento do Consumidor. São Paulo: Cengage Learning, 2011.

CAMARERO, C.; SAN JOSÉ, R. Social and attitudinal determinants of viral marketing dynamics. Computers in Human Behavior, v. 27, i. 6, p. 2292-2300, 2011.

CANNES LIONS. International Festival of Creativity. Todos os Grand Prix de Cannes. 2015. Disponível em: <http://cannes.meioemensagem.com.br/cobertura/2015/cannes/festival/festival/Todos-os-Grand-Prix-de-Cannes-em-2015.html>. Acesso em: 26 nov. 2015.

DOBELE, A. et al. Why pass on viral messages? Because they connect emotionally. Business Horizons, v. 50, i. 4, p. 291-304, 2007. 
HENNIG-THURAU, T. et al. Electronic word-of-mouth via Consumer-opinion platforms: What motivates consumers to Articulate themselves on the Internet? Journal of Interactive Marketing, v. 18, i. 1, p. 38-52, 2004.

HOLT, D. B. Why do brands cause trouble? A dialectical theory of consumer culture and branding. Journal of Consumer Research, v. 29, i. 1, p. 70-90, 2002.

IVO, N. V. S. Marketing Viral: a relação entre autoexpressão e o compartilhamento de mensagens publicitárias online. 2014. Dissertação (Mestrado em Administração)-Faculdade de Estudos Administrativos em Minas Gerais, 2014. Disponível em: <http://www.rede.bz/wp-content/files/biblioteca/naiara_ivo_autoexpressao.pdf $>$. Acesso em: 10 nov. 2015.

KAPLAN, A. M.; HAENLEIN, M. Users of the world, unite! The challenges and opportunities of Social Media. Business Horizons, v. 53, i. 1, p. 59-68, 2010.

KATZ, E.; LAZARSFELD, P. F. Personal Influence. Glencoe, IL: Free Press, 1955.

KELLER, K. L. Conceptualizing, measuring, and managing customer-based brand equity. Journal of Marketing, v. 57, i. 1, p. 1-22, 1993.

KLEIN, M. Self-Presentation Potential as a Significant Motivator for Sharing Video Advertisements on Social Networking Sites. 2015. Tese (Doutorado em Psychology and Film \& Media Studies)-Franklin \& Marshall College, Lancaster, PA, 2015. Disponível em: <https://dspace.fandm.edu/handle/11016/24110>. Acesso em: 10 nov. 2015.

LANDAU, M. J. et al. Embodied metaphor and the "true" self: Priming entity expansion and protection influences intrinsic self-expressions in self-perceptions and interpersonal behavior. Journal of Experimental Social Psychology, v. 11, i. 3, p. 79-87, 2011.

PÉREZ, M. L. Marketing boca a boca. Cómo conseguir que el consumidor hable de tu producto o marca. Proyecto de investigación. 2014. Disponível em: <https:// digitum.um.es/jspui/handle/10201/39206>. Acesso em: 10 nov. 2015.

PHELPS, J. E. et al. Viral Marketing or Electronic Word-of-Mouth Advertising: Examining Consumer Responses and Motivations to Pass Along Email. Journal of Advertising Research, v. 44, i. 4, Dec. 2004. 
SCHUTZ, W. C. FIRO: A Three Dimensional Theory of Interpersonal Behavior. New York: Holt, Rinehart \& Winston, 1966.

SIRGY, M. J.; AGUIRRE, R. A.; BOSNJAK, M. Moderators of the self-congruity effect on consumer decision-making: A meta-analysis. Journal of Business Research, v. 65, i. 8, p. 1179-1188, 2012.

SIRGY, M. J. Self-Concept in Consumer Behavior: A Critical heo-view. Journal of Consumer Research, v. 9, i. 3, p. 287-300, Dec. 1982. Disponível em: <http://www. jstor.org/stable/2488624?seq=1\#page_scan_tab_contents>. Acesso em: 10 nov. 2015.

SOLOMON, M. R. O comportamento do consumidor: comprando, possuindo e sendo. Porto Alegre: Bookman, 2016.

SUNDARAM, D. S.; MITRA, K.; WEBSTER, C. Word-of-mouth communications: A motivational analysis. NA-Advances in Consumer Research, v. 25, p. 527-531, 1998.

TAYLOR, D. G.; STRUTTON, D.; THOMPSON, K. Self-enhancement as a motivation for sharing online advertising. Journal of Interactive Advertising, v. 12, i. 2, p. 13-28, 2012.

TOBIN, J. The irony of self-expression. American Journal of Education, v. 18, i. 2, p. 233-258, 1995.

VELLIQUETTE, A. M.; MURRAY, J. B.; EVERS, D. J. Inscribing the personal myth: the role of tattoos in identification. Research in Consumer Behavior, v. 10, i. 3, p. 35-70, 2006.

WRIGHT, G. Consumer-to-Consumer Online Sharing of Co-Creative Advertising Campaigns. 2015. Dissertação (Master of Commerce in Marketing)-College of Business and Law University of Canterbury, 2015.

\section{Como citar este artigo:}

\section{ABNT}

MOTTA, Jéssica; SCHARF, Edson Roberto. A autoexpressão como dimensão inovadora de motivação no compartilhamento de vídeos em redes sociais. RACE, Revista de Administração, Contabilidade e Economia, Joaçaba: Ed. Unoesc, v. 16, n. 3, p. 1059-1078, set./dez. 2017. Disponível em: <http://editora.unoesc.edu.br/index.php/ race>. Acesso em: dia/mês/ano. 


\begin{abstract}
APA
Motta, J., \& Scharf, E. R. (2017). A autoexpressão como dimensão inovadora de motivação no compartilhamento de vídeos em redes sociais. RACE, Revista de Administração, Contabilidade e Economia, 16(3), 1059-1078. Recuperado em dia/mês/ ano, de http://editora.unoesc.edu.br/index.php/race
\end{abstract}


